\section{A theoretical note on the aging of the visual system}

\author{
ROBERT H. POLLACK \\ University of Georgia \\ Athens, Georgia 30602
}

Although there is little agreement on a theory of aging to account for changes in visual sensory and perceptual functions, there is a striking concordance in the phenomenal findings. Sensory thresholds rise; acuity diminishes; temporal resolution, as measured by critical flicker frequency (CFF) and dark interval threshold (DIT), is impaired; primary geometric illusions increase in magnitude; embedded figures are more difficult to detect. Gregory (1957) and Layton (1975) speak of an increase in neurological noise; McFarland (1963) writes of increasing "oxygen want"; and Axelrod proposes increased stimulus persistence (Axelrod, 1963; Axelrod \& Eisdorfer, 1962; Axelrod, Thompson, \& Cohen, 1968). Recently, Pollack and Atkeson (in press) have used Eisdorfer's (Note 1) conclusion that thin neural fibers age more rapidly than thick ones and his postulation of thin efferent fibers which may exert a damping effect on incoming stimulation to account for and to extend the stimulus persistence notion. The net result of all these efforts is a rather unsatisfactory melange of hypothetical physiological mechanisms located all over the visual system and therefore difficult to study directly. At the same time, there is stronger and stronger behavioral evidence of a stimulus persistence mechanism underlying age changes in visual perception.

What follows is a very brief synthesis of some recent work which could place the stimulus persistence mechanism in the retina and thus allow (via the techniques of Whitten \& Brown, 1973a, 1973b) the future study of these mechanisms in old as compared to young primates.

Some recent work on primate eyes by Whitten and Brown (1973a, 1973b), on the one hand, and Sackitt's (1975) paper on the locus of the icon (stimulus persistence) in human subjects, on the other hand, offer the basis for a mechanism to account for increased stimulus persistence in the aged. In essence, Whitten and Brown found the following with their electrical recording technique:

(1) Stimulation of the retina with scotopic illumination produces a slowly decaying rod receptor response potential (RP) in rods. The magnitude of the response increases with increased luminance until the photopic range is reached.

(2) Photopic stimulation does not result in a delayed RP. Cones show no similar function unless they are overdriven, and then the RP is truncated. The cones therefore suppress the rod RP.

(3) The delayed rod RP reappears under conditions of hypoxia, clamped retinal circulation, and barbiturate administration.

Sackitt (1975) found the following:

(1) In a cone-free monochromatic human subject, the presentation of letters at high scotopic intensity resulted in rod saturation and no response by the subject. Termination of stimulation resulted in the perception of an image of the stimuli for a few seconds.

(2) Response to the image produced was greater than short-term memory.

(3) A normal subject presented with green letters for $50 \mathrm{msec}$ reported a following iconic image which was white.

(4) Equation of icon brightness across visible wavelengths results in a curve which duplicates the standard visual sensitivity curve for scotopic vision. The icon or stimulus persistence resides in the rods, therefore.

If the results of these investigations are put together with an assumption of gradually decreasing metabolic efficiency in the eye during aging, the result would be a gradually increasing chronic hypoxia (McFarland, 1963), which could trigger the release of the rod RP and thus increase stimulus persistence. This mechanism would hold for suprathreshold stimulation only. Whitten and Brown (1973b) point out that the cone suppression of the rod response should serve to improve acuity, maintain color saturation, and promote the temporal resolution of intermittent stimuli. Most findings on aging indicate a decrease of acuity, a loss of color vividness, and a drop in CFF. The mechanism described, coupled with the assumption of aging effects on oxygen uptake and transport, thus provides a basis for the increase in stimulus persistence which appears to manifest itself increasingly in the second half of the life span. The interaction between this aging process and particular stimulus conditions still needs further specification, but the paradox of stimulus persistence accompanied by an apparent increase of sensitivity to some phenomena in the aged [e.g., greater simultaneous contrast effects (McCarter \& Atkeson, 1977)] in a generally deteriorating visual system can be resolved.

\section{REFERENCE NOTE}

1. Eisdorter. C. Leaming in the aged: A bio-behavioral approach. Colloquium presented at the University of Georgia. Athens, Georgia, March 1972. 


\section{REFERENCES}

AxelRod, S. Cognitive tasks in several modalities. In R. H. Williams, C. Tibbits, \& W. Donahue (Eds.). Processes of aging (Vol. 1). New York: Atherton Press. 1963.

Axelrod, S., \& Eisdorfer, C. Senescence and figural aftereffects in two modalities. Joumal of Genetic Psychology, 1962, 100, 85-91.

Axelrod, S., Thompion, L. W., \& Cohen, L. D. Effects of senescence on the temporal resolution of somesthetic stimuli presented to one hand or both. Journal of Gerontology, 1968. 23, 191-195.

GREGORY, R. L. Increase in "neurological noise" as a factor in aging. International Association of Gerontology, Proceedings of the Congress, 1957, 4, 314-324.

Layton, B. Perceptual noise and aging. Psychological Bulletin, 1975, 82, 875-883.

McCarter, A., \& Atreson, B. M. Simultaneous brightness contrast in young and old adults. Experimental Aging Research, 1977. 3, 215-224.
MCFARLAND, R. A. Experimental evidence of the relationship between aging and oxygen want: In search of a theory of aging. Ergonomics, 1963, 6. 339-366.

Pollack, R. H., \& Atkeson, B. M. A life-span approach to perceptual development. In P. B. Baltes (Ed.), Life-span development and behavior. New York: Academic Press, in press.

SACKITT, B. Locus of short-term visual storage. Science, 1975. 190, 1318-1319.

Whitten, D. N., \& Brown, K. T. The time courses of late receptor potentials from monkey cones and rods. Vision Research, 1973, 13, 107-135. (a)

Whitten, D. N., \& Brown, K. T. Photopic suppression of monkey's rod receptor potential, apparently by a coneinitiated lateral inhibition. Vision Research, 1973. 13, 1629-1658. (b)

(Received and accepted for publication November 7, 1977.) 